\title{
BIOETHICS
}

RESEARCH LIBRARY

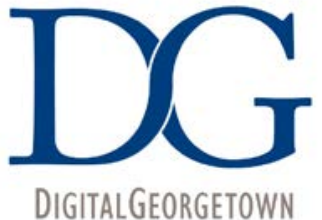

at GEORGETOWN UNIVERSITY

Bioethics Research Library at Georgetown University

https://repository.library.georgetown.edu/handle/10822/503786

The author made this article openly available online at the

Georgetown University Institutional Repository.

The Bioethics Research Library is collaborating with Georgetown's University Library to digitize, preserve and extend the history of Bioethics.

Please tell us how this access affects you. Your story matters.

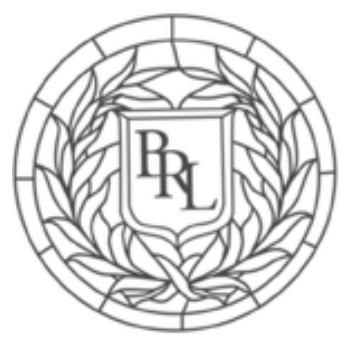

Visit us at https://bioethics.georgetown.edu/.

Copyright (C) 1991 The Johns Hopkins University Press. This article first appeared in Kennedy Institute of Ethics Journal, Volume 1 Issue 3; September 1991, pages 187-206.

Collection Permanent Link: hdl.handle.net/10822/503786

This material is made available online with the permission of the author, and in accordance with publisher policies. No further reproduction or distribution of this copy is permitted by electronic transmission or any other means. 


\section{Should Basic Care Get Priority? Doubts About Rationing the Oregon Way}

ABSTRACT. Recognition of the need to ration care has focused attention on the concept of "basic care." It is often thought that care that is "basic" is also morally prior. This article questions that premise in light of the usual definitions of "basic." Specifically, it argues that Oregon's rationing scheme, which defines "basic" in terms of cost-effective care, fails to pay sufficient attention to important ethical principles such as justice.

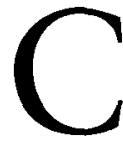

ONTROVERSY OVER THE CONCEPT of basic health care and its moral priority surfaced as long as a decade ago, as it became increasingly clear that health care rationing was both inevitable and morally necessary (Schelling 1979; Ozar 1983; Bailey 1986; Friedman 1986). The controversy was reflected in the debates about access to health care generated by the President's Commission for the Study of Ethical Problems in Medicine and Biomedical and Behavioral Research. Ever since the commission's commitment that "all citizens be able to secure an adequate level of care without excessive burdens," (President's Commission 1983 , p. 4) the concepts of "basic" care and an "adequate level" have been linked.

The Oregon Basic Health Services Act of 1989 has given new impetus to the confusion over the concept of basic care (The Oregon Basic Health Services Act n.d.; Morell 1990; Kitzhaber 1990-91, pp. 60, 64). The Act authorizes explicit rationing of health care for certain classes of Medicaid patients, giving priority to care identified as "basic." But while we have a sufficient grasp of the term "basic" to use it in titles of legislation and articles defending the legislation, our intuitions may not be adequate to tell us in hard-nosed, practical terms, what the moral priorities should be.

Basic care is variously thought of as inexpensive rather than costly, 
preventive rather than curative, low tech rather than high tech, primary rather than secondary or tertiary, and, if dealing at all with the treatment of existing illness, acute rather than chronic. If most of these occur simultaneously in one set of health care services, it usually seems obvious that those services are high priority.

It is becoming obvious, however, that these characteristics do not always occur together. What are we to make of a preventive, low tech, primary service that is very expensive per unit of benefit-some health education programs, for example? What do we make of a tertiary, high tech intervention that is inexpensive and an effective treatment of an acute illness? A first question, then, is whether a service counts as basic care if it qualifies on some counts but not others.

A second question has to do with the link between the concept of basic care and the moral question of what care deserves moral priority. We are interested in which care is "basic" probably because we believe we can get some moral or policy mileage out of the label. The working assumption is that care that is basic in some sense has moral priority.

If, however, basic is defined in relation to notions of inexpensive, preventive, low tech, primary, or acute, then it is an open question whether a basic intervention necessarily deserves moral priority. It is not even obvious that all such care efficiently produces health benefits; even if it turns out that it does, the question remains whether the care satisfies other moral criteria such as equity.

Some people argue that basic health care is morally prior by definition because it refers to a first tier of health services that are "fundamental" or "foundational" in the sense that they have moral priority over a second tier of services. Thus, one would figure out a ranking for care, draw a line, and then label the morally prior segment "basic." This makes basic care morally prior analytically; whatever care has priority is simply called basic.

But with this approach, all the work of figuring out what is morally prior remains to be done. Aggressive, high tech, life-saving experimental care could turn out to be basic according to someone who gave moral priority to saving life at all costs. Often, however, something more complicated is going on when "basic" and morally prior are linked. The dictionary definitions of basic do not necessarily imply moral priority. They refer to forming the essence, fundamental, constituting or serving as the basis or starting point. They convey the notion of being simple, elementary, uncomplicated, or first in some nonmoral ordering. 
The term basic turns out to be deceptively ambiguous. On the one hand, it seems like something can be labeled basic without implying anything about its moral claims or priority. If basic is defined without reference to moral concepts-for example, as simple, first in order, or elementarythen we still have not established whether such care deserves moral priority. If it turns out that such care is also often seen as morally prior for some reason, then the ambiguity in the term creates a play on words in which basic care defined in nonmoral ways is held to be morally basic as well.

But terms such as "fundamental" or "of the essence" might be thought to come first in priority. Even in certain nonmoral uses of the term, basic implies coming first in a sequence. Basic math courses come before more complex courses; basic life-saving before advanced. This ambiguity has caused serious problems in the debate over health care rationing. I believe the term "basic" gained significance from a desire to claim that because certain health care is basic in a completely nonmoral sense, it is basic in the sense of being morally prior.

Before analyzing these questions about the meaning of "basic care" and its moral priority in rationing schemes I want to briefly consider some of the initial assumptions that prompted these schemes.

\section{SOME INITIAL ASSUMPTIONS ABOUT RATIONING CARE}

The Oregon experiment and many other programs attempting to give priority to care considered basic are built on some controversial assumptions.

First, proponents of a priority for basic health care consider rationing inevitable. They generally claim that the only choice is between subconscious, hidden rationing through mechanisms that prohibit access to the health care system (lack of insurance, gaps in coverage, and burdens that make access so unattractive that getting care is not worth it) and conscious, explicit rationing with public deliberation over what care deserves moral priority. On this, they are certainly correct. Those who think that we would have enough resources if we simply cut the fat out of the system and eliminated useless medical services, fundamentally misunderstand the problem (Veatch 1990). Even if we could eliminate every medical intervention that offered no net benefit, there would still be marginally beneficial services that offer slightly more benefits than risks-that are extremely inefficient and costly. Unless we have infinite resources, some of these services ought to lose out to others that are more effective or more fair.

Second, defenders of Oregon-type schemes assume that rationing can 
be done by quantifying the values and moral claims at stake. They make use of measures of Quality-Adjusted Life Years (QALYs) (Weinstein and Stason 1977), a Quality of Well-Being Scale (QWB) (Kaplan and Bush 1982), or a Healthy-Years Equivalent Scale (Mehrez and Gafni 1989).

Clearly, the goods and harms at stake are extremely difficult to quantify. They include not only the values of life and health, but also the disutilities of death, pain, suffering, and immobility. Reducing these to numbers may offend some, but the only alternative is to make rough rankings of alternatives without the benefit of disciplined and systematic comparisons. It may be quite appropriate to ask patients to make simple choices subjectively and without quantification, but health policy planning involves extremely complex choices among what appear to be incommensurable alternatives, forcing some more orderly system for comparison. I cannot fault the health planners in Oregon and elsewhere for attempting to quantify; quantification is not inherently immoral. The strategies for doing so have become increasingly sophisticated. If rationing is morally necessary, then some above-board system subject to public scrutiny and debate should be used.

A third assumption is that ranking alternatives is at least somewhat separable from the question of how large the pool of resources for health care should be. Many have criticized the Oregon project because it attempts to ration care only for the poor - the Medicaid insurance pool (Daniels 1991). Even worse, it excludes rationing for the aged, blind, and disabled leaving the very poor to divide up a clearly inadequate pool of resources (Oregon, Senate Bill 27, sec. 3).

The criticism would be justified if those participating in developing the Oregon plan ignored efforts to cut elsewhere. It would be far better to have a single payer or universal insurance system with the rationing affecting all in the system. But advocates make clear that they would rather be allocating all of the health care resources. That, however, is not an option open to them. It might be argued that their task is so inherently tainted that they should simply refuse to address the questions of priorities among the poor; sabotaging the system might be a means of reforming it.

The alternative is to struggle with the immediate problem. Very poor people are in need of health care, and Medicaid funds are available to meet only a portion of those needs. I do not see how we can fault those who tackle the immediate problem of attempting to determine which of the immediate needs are morally prior. If that were done without any 
concern for the broader questions of getting coverage for those who do not qualify for Medicaid, one might be suspect. However, Oregon is striving to develop health insurance for the uninsured working poor and to incorporate Medicare and other insurance into the allocation.

\section{WHAT COUNTS AS BASIC?}

It is time to press for clarity in the use of the term, "basic." In many cases, care that is basic in the nonmoral sense of the term-low tech, preventive, primary, inexpensive, or care for acute illness - also possesses characteristics that tend to make it basic in the sense of morally prior. Examining the kinds of care considered basic, may help shed light on this relationship.

Low Tech Care. When proponents of basic care think about the technology involved, they focus on simple, easily understood remedies rather than on high tech electronic machinery or radical, complex surgery. Many critics of medicine have been skeptical about complex remedies. Only 20 percent of participants at the community meetings designed to gather grassroots opinions about community values, favored funding transplants; another 39 percent were uncertain (Crawshaw et al. 1990, p. 443.).

Religious critics of medicine have long favored simplicity. John Wesley (1785), the founder of Methodism, wrote a laymen's home remedy manual called Primitive Physick that reflected a deep suspicion of complex, esoteric, secret remedies of professional healers. It went through more than twenty editions and was a best seller in eighteenth century England. Likewise, Thompsonians in nineteenth century America pressed for simple, natural remedies; they considered complex treatments interventionistic. Protestant proponents of a strong doctrine of human fallibility have been skeptical that humans could make use of complex, high tech interventions without losing control and ending up doing more harm than good. This instinct also stands behind the medical moral slogan primum non nocere, "first of all, do no harm."

But is there something intrinsically morally preferable to treatments that are simple? One might argue that there is, but more likely, simplicity is preferred only instrumentally; simple, low tech procedures are believed to produce more benefits per unit of investment and to produce them in a more reliable fashion.

Prevention. Interventions are also considered basic if they focus on prevention rather than cure. According to Michael Garland, president of 
Oregon Health Decisions, which in 1990 sponsored forty-seven meetings throughout the state to determine community values, prevention was "vigorously advanced" (Garland and Hasnain 1990, p. 17; Oregon Health Services Commission 1991, appendix F). In earlier 1988 meetings, which anticipated the 1990 activities, participants were asked to classify care on a four-by-four grid as low, medium, or high priority care. Four kinds of health care (critical care, long-term, short-term, and preventive) were crosstabulated with four stages of the life cycle (infants, children, adults, and the elderly). Preventive care was ranked "high" for the first three stages of the life cycle and, by far, was the most highly favored type of health care (Crawshaw et al. 1990, p. 443).

John Kitzhaber, the president of the Oregon State Senate and political shepherd of the Oregon Basic Health Services Act, contrasts the expenditures for high-cost transplants for about thirty Medicaid patients who would need them in the next two years with spending the same money on "basic preventive" care for nearly 3,000 people without health insurance coverage implying the latter investment is wiser (Kitzhaber 199091, p. 59). It is impossible to tell whether he is using basic to qualify preventive, implying that some preventive care is not basic, or whether it is a synonym for preventive. It is clear, however, that the proponents of the Oregon Basic Health Services plan see preventive care as high priority, as closely associated with what they consider basic.

Is there something about preventive care per se that should give it moral priority? It is often said that "an ounce of prevention is worth a pound of cure." Preventing illness or injury avoids the tragedy and misery of illness that one endures even if cure is possible. But consider a hypothetical case of a preventive and a curative intervention that produce the same net benefit per unit of investment of resources (even accounting for the burdens of disease preceding the curative intervention). Would there be a moral preference for prevention? It is difficult to see why. In fact some people feel a moral priority for rescue (Hadorn 1991).

A preference for prevention might derive from the belief that prevention is usually more efficient at producing health benefits, rather than because there is something intrinsically attractive about the preventive mode. Such a belief is plausible, but it need not always be true. Evidence is required to demonstrate that preventive interventions are more efficient in producing benefits. Even if they are, we shall see later that fairness may generate a claim for attempting to cure already sick patients, especially those who are particularly poor-off. 
Regarding the thirty transplant patients and the 3,000 patients who could get basic preventive care for the same money, it seems plausible that more quality-adjusted life years (QALYs) would come from the prevention intervention. However, if there were a high probability of graft survival and many life-years per graft, that might not be the case. It is not even clear how we calculate the benefits. Presumably, many recipients of preventive care will get no benefits; they would have remained healthy without it. Some will get modest benefits, and a small number might have their lives saved. Some prevention might, like transplants, be thought of as significantly benefitting a small number at a large expense per person.

Primary Care. A third kind of care that is often considered basic is primary care, that is care provided outside the hospital setting. Often it is both low tech and preventive, but it need not be either. For example, a diagnostic CAT scan in a doctor's office is high tech, and penicillin for a strep throat is curative, but both are considered primary care.

Once again there seems to be no intrinsic merit in primary care. Insofar as it is morally preferable, it is likely to be because primary care tends to have some characteristic that makes it attractive. Perhaps that characteristic once again is the great tendency for primary care to be cost-effective or efficient in producing benefits per unit of resources invested.

Inexpensive Care. A common theme among care that is low tech, preventive, and primary, appears to be that often such care is inexpensiveespecially in comparison to the stereotypical high tech organ transplant, chronic maintenance of the persistently vegetative patient, or radical cancer surgery. Perhaps the real feature of care favored by the rationers who speak of basic care is that it is inexpensive.

However, low tech, preventive, primary care is not necessarily inexpensive, although it may tend to predict low-cost care. Intensive health education programs targeted at hard to educate sectors of the population could turn out to be expensive. On the other hand, a high tech, curative, tertiary intervention could just happen to be cheap per unit of treatment, and some high tech, tertiary care, diagnostic procedures could be inexpensive on a per test basis.

But can the case be made that care is basic in the sense of being morally prior simply because it is inexpensive per unit of intervention? If cost is the relevant criterion (and I am not convinced it is), then it would seem that cost per unit of benefit rather than cost per unit of intervention would be what was relevant. But before turning to cost-effectiveness as a possible 
criterion for morally basic or priority care, there is one additional working criterion that should be explored: acute care.

Acute care. Thus far the kinds of care that have been associated with basic (low tech, preventive, primary, and inexpensive) are theoretically compatible; care could be all of these simultaneously. Some people even speak as if the categories were cumulative-care that is low tech, preventive, primary, and inexpensive would be the most basic of all.

We have seen that there is reason to doubt that care is more basic in the sense of morally prior simply because more of these characteristics are present. There is no reason to assume it is more basic, if more of them are present. In fact there is one category of care that often intuitively makes the lists of basic treatments which is not compatible with preventive care: care for acute illnesses, especially safe, simple, and sure interventions. Penicillin for pneumonia surely qualifies; even though it is not preventive, it is low tech, primary, and inexpensive, and more significant, seems to be highly cost-effective. If simple precautions are taken to rule out the history of anaphylaxis, penicillin is probably one of the most cost-effective treatments yet discovered.

\section{COST-EFFECTIVENESS AS A POSSIBLE CRITERION OF BASIC CARE}

Analysis of the literature on the Oregon program and similar rationing efforts makes overwhelmingly clear that the real moral basis for giving priority to care that is labeled basic is the assumption that basic care is the most cost-beneficial or cost-effective care, offering the most benefit per unit of resources invested. ${ }^{1}$ The dominant operating model is that planners should identify the resource allocation that will produce maximum overall aggregate benefit, normally focusing on health benefits. Health benefits are defined very broadly. The Principles of the Oregon Citizens Health Care Parliament, for example, define health-related quality of life as including "mental, social, cognitive and self-care functions as well as a perception of pain and sense of well-being" (Citizens Health Care Parliament 1988, p. 2).

Literature from the various Oregon events includes many references to cost-effectiveness or its equivalent. According to the principles emerging from the 1988 Oregon Citizens Health Care Parliament, "In general, a high priority health care activity is one where the personal and social health benefits/cost ratio is high" $(1988$, p. 2$)$. Key players in the Oregon process say prevention is given high priority because it "leads to health benefits being achieved at the lowest cost (compared with treating problems 
after they occur). Thus the greater efficiency, or benefits received per dollar spent, the greater the value of the health service" (Crawshaw et al. 1990, p. 443). There are several serious problems involved in concluding that basic care is morally prior because it is cost-effective.

Is Basic Care Necessarily Cost-Effective? The first problem with this linkage is the empirical presumption that care that is basic in the nonmoral sense is always cost-effective. As I noted earlier, there is no reason why basic care has to be cost-effective; evidence needs to be mounted for each intervention to establish the link and to show that more complex care is not cost-effective.

Can Condition/Treatment Pairs Be Ranked? The approach in Oregon is to rank diagnoses linked with general, broad treatment strategies (e.g. "medical therapy" or "surgery"). No effort is made to describe specifics of individual treatments or preventive actions. For medical therapy, for example, no mention is made of specific drugs, dosage forms, routes of administration, dose levels, or length of administration. The original rankings, released in May 1990, covered 1,600 diagnoses; the second ranking reduced the number of diagnosis/treatment pairs to 709 by combining groups of related diseases (Oregon Health Services Commission 1991, appendix J).

The critical point is that if the goal is to maximize net benefits by identifying the most cost-effective interventions, it is inconceivable that a ranking by diagnosis will do any good. Even for pneumococcal pneumonia, tuberculosis, or peritonitis - the three highest-ranking disorders in the second list-some aspects of treatment are surely very inefficient and costineffective. Even if some safe, simple, and sure pharmaceutical would quickly and cheaply cure the pneumonia (and thus qualify as basic care), there still must be some treatments for pneumonia-perhaps hospitalization in an ICU, for example-that are very expensive and offer only marginal benefit. ICU hospitalization would surely then not be basic in the sense of having moral priority the way that the inexpensive drug would be. Even when ICU hospitalization is significantly beneficial, there will be decreasing marginal utility for additional days of stay (Veatch 1986).

For any high priority disorder, some treatments will be extremely inefficient. For even low priority conditions, some treatments will be very cost-effective. Any commitment to maximizing efficiency through costeffectiveness analysis requires that each possible intervention for each possible condition be ranked separately. 
The inevitable bias of the rankers. The methods used in Oregon are extremely sophisticated in integrating subjective judgments about life quality with assessments of morbidity and mortality. Still, as the Commissioners themselves would surely admit, biases will creep in.

Several sources of data are combined to arrive at rankings. First, a telephone poll of 1,000 residents (presumably chosen at random) was conducted, introducing the well-known bias in favor of the kinds of people who have telephones. Another input may pose more serious bias problems. Participants in the community meetings, which were an important step in determining community values, were far from a random sample of Oregon citizens. Likewise, of the 560 people surveyed at nineteen meetings held as part of the earlier "Oregon Health Priorities for the 1990s" project, 56 percent of the respondents worked in health care. Health workers may well be more committed to prevention or have more doubts about longterm care for younger people than the general population. In addition, 64 percent were women, and only 5 percent were under 25 years of age (Crawshaw et al. 1990, p. 442).

Historically, health workers have been committed to consequentialist modes of ethical reasoning. Moral consequentialism dominates the Hippocratic Oath and the moral tradition that traces its roots to that ethic. It is utilitarian consequentialism that provides the moral foundation for the cost-benefit and cost-effectiveness analysis that has dominated the movement for rationing care. There is good reason to suspect that the priority for cost-effective care revealed in the two sets of community meetings (Garland and Hasnain 1990, p. 17) derives from the oversampling of health workers and people who share their inclinations.

The Oregon Health Services Commission, the legislatively created body with the mandate to develop the rankings of priority disorders, has a similar bias. This commission chose the computer formula for the initial rankings, and had the responsibility to review the computer rankings and make subjective, "common-sense" adjustments. Although health professionals make up a tiny proportion of the general public, the law requires that they be a majority on the commission (Oregon Senate Bill 27, sec. 4, subsec. 1). The makeup is five physicians, a nurse, and social worker, along with the four health consumers. The decision to give priority to the most beneficial care and to use a formula that focuses exclusively on calculating aggregate net benefit is just what one would expect from a commission dominated by health professionals. It is the same commitment to utilitarian reasoning seen, for example, in the professionally dominated 
panels of the United Network for Organ Sharing, the national body responsible for allocating human organs for transplants.

Finally, according to Oregon State Senate President Kitzhaber, "a panei of health care experts" not representatives of the general public of subscribers will decide on the federal Health Care Financing Administration's waiver of Medicaid rules, which is required for the Oregon rationing plan to go into effect (1990-91, p. 64). The choice of the methods for ranking, the moral principles for ranking, and the value choices that shape what constitutes benefits in health reflect the unique value commitments of the members of the commission and those who attended the community meetings.

\section{IS COST-EFFECTIVENESS THE CORRECT CRITERION?}

As long as the goal is to maximize the benefit in aggregate per unit cost, the approach used by the Oregon Commission in its initial rankings (May 1990) was sophisticated even if it raised some problems (Oregon Health Services Commission, 1991.)

Their formula measured the cost per quality-adjusted life year and ranked diagnosis/treatment pairs on that basis. By dividing the cost per year by a Quality of Well-Being Index, the quality of the life of the patient receiving the treatment was factored in.

But the question remains whether it is necessarily correct to treat care as basic (morally prior) simply because it is cost-effective. That is what utilitarian ethical theory calls for, but it is at odds with many of the most significant moral traditions of our culture.

Many aspects of the Judeo-Christian tradition are explicitly nonutilitarian. So is Kantian ethics. Most critically, the tradition of liberal political philosophy -including the Bill of Rights of the American constitutionrecognizes moral right-making characteristics that are independent of efforts to maximize good results (such as quality-adjusted life years). Among the most conspicuous of such moral considerations are the duties of preserving life, respecting autonomy, and promoting a just or equitable distribution of benefits. These are sometimes thought of as fundamental principles. They could be said to be characteristics that could make care basic in the moral sense of the term.

Consideration of these characteristics can lead to understandings of "basic care" that are radically different from the cost-effectiveness approach of the Oregon plan. Fredrick Abrams, associate director of the University of Colorado Center for Health Ethics and Policy, claims that 
nothing could be more basic "than saving the life of someone who finds the resulting quality of life, albeit diminished, nevertheless acceptable" $(1990$, p. 2). He argues that costly care for a quadriplegic (at $\$ 300,000$ for the first year and $\$ 100,000$ yearly thereafter) is "basic care" because it treats those whose need is greatest.

Likewise, David Ozar presumes that by establishing different levels of health care need we can identify what is basic by identifying where the need is greatest (1983, p. 129).

Let's look at how incorporating these principles alters our notion of basic care.

Respect for Autonomy. As an alternative to assigning moral priority to the care that produces health benefits most efficiently, consider the view that a patient's voluntary exercise of health risky behavior is relevant. Certainly this is both controversial and difficult to operationalize, but serious proposals are being floated to, for example, create separate insurance pools that would fund care for smokers from fees on tobacco (Veatch 1974), or to lower the priority for liver transplant for those are suffering from alcohol-related end-stage liver disease (Moss and Siegler 1991).

The notion here is that respect for personal autonomy in lifestyle is morally important, but that common insurance funds such as Medicaid should not bear the costs of voluntary, health risky behavior, or at least the voluntary component should lower the care's priority. If possible, separate funds should be collected to finance such care and policymakers should take this into account in deciding priorities for use of public health insurance funds.

My point here is not to make the case for incorporating a principle of autonomy in the priority-setting process, but rather to suggest that those who set priorities cannot presume that cost-effectiveness is the only criterion. They must confront the argument that health care needs that result from voluntary lifestyle choices deserve lower priority. In most of his writings Robert Kaplan, the chief architect of the Oregon statistical formula, simply presumes a cost-effectiveness grounds for establishing priorities, but in one essay he and a co-author reveal they are aware of the relevance of risks being voluntary (Mendeloff and Kaplan 1989, p. 362).

Equity. Justice or equity is a second principle challenging the view that allocations should be based solely on cost-effectiveness. The most serious problem with any formula such as the Quality-Adjusted Life Years or 
Quality of Well-being Scale is that, in principle, they cannot take into account how the health benefits are distributed in the affected population. The Oregon plan gives pause to one who worries about justice in distribution because it sets out to expand coverage to include those at a higher percentage of poverty by reducing the number of disorders covered for the poorest members of the population. Thus some admittedly beneficial care is taken from the worst-off in order to give benefits (admittedly greater benefits in aggregate) to those who are slightly better-off. This is attractive to those committed to cost-effectiveness, but surely controversial to those committed to promoting greater equity. The new Medicaid enrollees cannot be thought of as well-off, but they are better-off than those who now qualify.

The question of equity is raised in the choice between transplants for thirty patients and preventive care for 3,000 noted earlier. Depending on how the benefits of preventive care are conceptualized, it may be more fair to provide the transplants, even if preventive care results in a greater aggregate net benefit. If the benefits of preventive care are seen in terms of a very small benefit to each of the 3,000 patients, who are much better off than the thirty who face death without transplants, and equity requires giving benefits to those with the greatest need, the transplant patients would clearly have the stronger claim. If, on the other hand, we think of the beneficiaries of the prevention program as some small, unidentifiable group who receive great, even life-saving, benefits, those patients may be as poorly-off or worse-off than the transplant patients, and could have claims of equity as great as or greater than the transplant candidates. The number of patients or the number of QALYs in aggregate would not be significant, only the welfare of the worst off.

Cost-effectiveness analysis is indifferent to such shifts of benefits from the worst-off to those who are better-off. In fact, insofar as a shift to better-off patients increases net utility, it would be looked upon favorably.

Consider two groups of 100 patients, one living at 0.3 on the Quality of Well-Being Scale, and the other at the 0.7 level. Suppose that a fixed resource investment could raise either group by 0.2 years per person per year for the same number of years - leaving the first group at the 0.5 level or the second group at the 0.9 level.

From the point of view of cost-effectiveness analysis (and the formula used by the Oregon Commission), one should be indifferent to whether the more miserable $(0.3)$ patients are raised to a well-being level of 0.5 or the better-off $(0.7)$ patients are raised to 0.9 . Exactly the same aggregate 
benefit accrues for the same investment. As far as I can tell there is no way the Oregon formula (in either its cost-benefit or net benefit version) would record any difference between these two interventions.

Yet, it seems reasonable to feel a moral preference for using the resources to benefit the group that is much worse-off. That could only be true if the distribution of benefits was morally relevant in addition to the amount of benefits per unit of resources. If need is morally relevant to distributing health care resources, we might want to say that one criterion for (morally) basic care is that it provides benefits to those in greatest need. Providing care to those with the greatest need might even take precedence over care that produced somewhat greater aggregate net benefit for the better-off patients. When equity conflicts with efficiency, it is not a foregone conclusion that the care that produces the maximum increase in QALYs per unit of investment is preferable.

\section{DOES THE OREGON APPROACH INCLUDE EQUITY?}

Proponents of the use of QALYs, QWB scales, or other cost-benefit data to determine which care is basic might argue that their approach does consider equity as well as efficient production of overall aggregate net health benefits. The February 1991 rankings do provide at least three adjustments that could, in theory, take justice into account: (1) The Oregon officials modified the formula to use net benefit rather than cost-benefit ratio as a basis for the computer ranking; (2) they arranged the condition/ treatment pairs into seventeen "categories"; and (3) they made a final adjustment in the rankings that could make them more equitable. Although each of these might shift the rankings to better reflect concern for justice in distribution, I fear that even in combination they may not do the job.

Shifting to net benefits. The February 1991 rankings provided a computer-generated score for each of the condition/treatment pairs that used net benefit (the average QWB after treatment minus the average QWB before treatment multiplied by the number of years the benefit would accrue) instead of the earlier cost per unit of benefit (Hadorn 1991, p. 2220). This has the effect of giving a high ranking to a treatment that a patient deems of great benefit, even if it is relatively expensive and might consequently not score as well on a scale taking cost into account.

However, this approach still does not deal directly with justice in the sense of examining the distribution of benefits and giving moral priority to the sickest patients. A substantial benefit will be ranked highly whether it accrues to a very sick patient or to one who is quite well-off. It still 
would not differentiate between the treatment raising patients from 0.3 to 0.5 on a QWB scale and one raising patients from 0.7 to 0.9 .

Use of net well-being also cannot take into account other dimensions of justice-the fact that some diseases differentially afflict worse-off and better-off patients, for example. Insofar as justice requires arranging social practices so as to benefit the least well-off, it would require giving priority to the diseases afflicting worse-off persons. Pressing this analysis one step further, one could imagine that judgments about benefit vary depending on how poorly-off one is. For example, middle-class whites and lowerclass blacks might assess the benefits of treating sickle cell crisis differently. Some decision will need to be made regarding which assessment counts. Justice suggests using the assessment of the least well-off (perhaps even if the treatment primarily helps those better-off).

It is striking that apparently no effort is made in typical cost-effectiveness studies (the Oregon Commission's or any others) to generate data on distribution of benefits that are as sophisticated as that produced for determining aggregate benefits. If the kind of intellectual talent and finances put into measurement of the amount of benefit were devoted to measuring the distribution of benefits, it might be possible to calculate which condition/treatment pairs benefit the worst-off.

For example, the calculation of net benefit has within it an empirically generated estimate of how poorly-off a patient is on a quality of wellbeing scale prior to the treatment being assessed. One could also use these data to rank condition/treatments pairs on the basis of which persons are worst-off before treatment. In addition, if economic data were collected about who suffers from the various conditions, one could calculate the standard distribution of the benefits among different economic groups.

There is also the question of how much of the possible benefit for a given condition should be funded. Earlier, I suggested that specific interventions within a given treatment with marginal benefits might be eliminated; then virtually no patient would get every last benefit. Justice suggests that the worse off the patient, the greater the percentage of maximum benefit that patient should receive.

Arranging Condition/Treatment Pairs by Categories. The second way in which justice might be factored into the Oregon rankings is at the stage when condition/treatment pairs are arranged into what the Commission calls "categories." Seventeen categories were established and ranked, and then the 709 pairs were assigned to a category. For example, one category (the highest ranking) included conditions that were acute and fatal, but 
treatment would prevent death and lead to a full recovery. Another category included conditions that were chronic and nonfatal, but a one-time treatment improved quality of life. The condition treatment pairs were ranked within the category based on the computer-generated net benefit score. For example, medical therapy for pneumococcal pneumonia was a high ranking condition/treatment pair within the first category; surgery for benign neoplasms of the digestive system ranked high in the second category mentioned above. In theory, the ranking of the categories could permit justice to come into play.

To rank the categories, each commissioner scored each category on three "attributes": (1) value to society; (2) value to an individual at risk of needing the service; and (3) essential to a basic health care package (Oregon Health Services Commission, 1991, appendix G-8). These attributes were in turn made up of some of the thirteen "health-related values" seen as important at the community meetings (Oregon Health Services Commission, 1991, appendix G-7).

For our purposes, what is relevant is that one of the ten "values" in the "value to an individual at risk" attribute is "equity." Theoretically, then, equity could show up in the ranking of the categories. ${ }^{2}$ As a practical matter, however, it simply could not happen in any significant way. First, a commissioner would have to believe that "equity" was relevant in deciding whether something was of value to an individual at risk; I fail to see how equity could be a serious consideration in the question of "value to an individual." And even if it does get incorporated somehow, equity is only one of the ten values that feeds into one of the three attribute scales that is then used to rank the categories, which in turn ranks the specific condition/treatment pairs. The equity consideration is so remote to the ranking and so implausibly related to the attribute of "value to an individual" that justice simply can not be expected to show up in this process. If it did, it would only affect the ranking of broad categories of treatment. There is simply no way the justice of a particular treatment can be reflected at this stage.

The Final Adjustment in the Rankings. After net benefits of condition/ treatment pairs were ranked by computer and categories were ranked by the commissioners, the commission spent a week making a final adjustment in the ranking. They used "professional judgments and their interpretation of the community values to re-rank items" using a "reasonableness" test (Oregon Health Services Commission 1991, Appendix G-15). It is only at this point that justice might have any real chance of surfacing. There 
is reason to suspect, however, that justice still does not play any significant role in the rankings. Since the process is subjective, it is hard to know the reasons in the minds of the commissioners. There is reason to suspect, however, that in the end justice does not play any significant role in the rankings. At the least it is clear that the commissioners made no commitment at all (in money, time, or brain power) to developing a sophisticated methodology developed to measure objectively the distribution of benefits. Moreover, throughout the process the focus was on identifying which care was basic, not which care was fair. Since basic care was closely identified with care that was cost-effective, there is every reason to believe that the final adjustment process only solidifies the high priority for care that was basic in the nonmoral sense, not care that had uniquely high moral priority based on criteria other than those of cost-effectiveness.

\section{CONCLUSION}

Explicit rationing of health care based on its moral priority cannot be avoided. Those who have undertaken experiments to develop the methodology to do so deserve our gratitude and respect. In the effort, however, we need to be on guard against conceptual and moral assumptions that cannot be supported. The assumption that care that is basic in the sense of being simple, low tech, primary, inexpensive and/or preventive, will be cost-effective and therefore will be basic in the sense of deserving priority is suspect. It is perhaps better that we go back to speaking, as the President's Commission did, of "an adequate level" of care or simply of a morally appropriate level allowing for more serious moral work to determine what that is.

\section{NOTES}

1. A technical qualification is necessary. In the first (1990) priority ranking, the Oregon project explicitly used cost per unit of net benefit as the criterion. The controversy surrounding that list led to revisions in the methodology. The Health Services Commission Report in their February 1991 rankings substituted net benefits alone for cost per unit of net benefit as the initial basis of their (unadjusted) ranking (Oregon Health Services Commission, 1991, appendix G-15). Elsewhere in the commission's report, however, there are implications that cost-benefit ratios were not only calculated but used (1991, appendix D-1, D-2, D-10). They make clear, however, that one reason to ignore costs would be that their data showed that, in comparison to net benefits, 
cost was a factor that was not influential in the ranking (Oregon Health Services Commission 1991, appendix D-19).

2. The Oregon Health Decisions community meetings and earlier Health Parliament both record evidence of concern about equity. A summary of the "values" emerging from the community meetings cites five values including equity (Garland and Hasnain 1990, p. 17). One of the fifteen principles adopted by the 1988 Citizens Health Care Parliament stated that "both efficiency and equity should be considered in allocating health care resources" (Citizens Health Care Parliament 1988, p. 3).

While this is surely an opening to equity, it is less clear how it actually gets incorporated into decisions. First note that equity is the fifth of five themes (called "values") coming from the community meetings. The first four all relate in intertwined ways to producing aggregate health benefits. The terms include some familiar to our exploration of basic care: prevention, quality of life, costeffectiveness, and ability to function (Garland and Hasnain 1990, p. 17). I would contend that quality of life and ability to function are, in fact, elements of a complex that forms health-related well-being, that prevention is a mode of care believed often to achieve that well-being efficiently, and that costeffectiveness is synonymous with a principle of producing the good (healthrelated well-being) as efficiently as possible. Neither prevention nor cost-effectiveness is really a value in the technical sense (nor is equity). The only real value (desired end state) is well-being. Quality of life and ability to function are two important elements; prevention is a means to that end.

If this is correct, the first four of the five "themes" or "values" are really related to efficient production of health-related well-being as defined in a particular way. At most, equity (the fair distribution of this well-being) counts as one of five considerations.

Likewise, only one of the fifteen principles from the Citizens Parliament commits to equity as well as efficiency. At most, it represents a minor part of the agenda.

\section{REFERENCES}

Abrams, Fredrick. 1990. The Basis of Basic Care: Before We Decide to Provide 'Basic Care' For All, We Must Decide What 'Basic' Means. FrontLines 7 (October): 2, 11.

Bailey, Mary Ann. 1986. Rationing Medical Care: Processes for Defining Adequacy. In The Price of Health, ed. George J. Agich and Charles E. Begley, pp. 165-84. Boston: D. Reidel.

Citizens Health Care Parliament. 1988. Quality of Life in Allocating Health Care Resources. Portland, OR: Oregon Health Decisions. 
Crawshaw, Ralph; Garland, Michael; Hines, Brian; and Anderson, Barry. 1990. Developing Principles for Prudent Health Care Allocation: The Continuing Oregon Experiment. Western Journal of Medicine 152: 441-46.

Daniels, Norman. 1991. Is the Oregon Rationing Plan Fair? Journal of the American Medical Association 265: 2232-35.

Friedman, David D. 1986. Comments on 'Rationing Medical Care: Processes for Defining Adequacy.' In The Price of Health, ed. George J. Agich and Charles E. Begley, pp. 185-97. Boston: D. Reidel.

Garland, Michael J., and Hasnain, Romana. 1990. Grassroots Bioethics Revisited:

Health Care Priorities and Community Values. Hastings Center Report 20 (5): 16-18.

Hadorn, David C. 1991. Setting Health Care Priorities in Oregon: Cost-effectiveness Meets the Rule of Rescue. Journal of the American Medical Association 265: 2218-25.

Kaplan, R. M., and Bush, J. W. 1982. Health-Related Quality of Life Measurement for Evaluation Research and Policy Analysis. Health Psychology 11: 61-80. Kitzhaber, John. 1990-91. A Healthier Approach to Health Care. Issues in Science and Technology 7: 59-65.

Mehrez, Abraham, and Gafni, Amiram. 1989. Quality-adjusted Life Years, Utility Theory, and Healthy-years Equivalents. Medical Decision Making 9: 14249.

Mendeloff, John M., and Kaplan, Robert M. 1989. Are Large Differences in 'Lifesaving' Costs Justified? A Psychometric Study of the Relative Value Placed on Preventing Deaths. Risk Analysis 9: 349-63.

Morell, Virginia. 1990. Oregon Puts Bold Health Plan on Ice. Science 249: 46871.

Moss, Alvin H., and Siegler, Mark. 1991. Should Alcoholics Compete Equally for Liver Transplantation? Journal of the American Medical Association 265: 1295-98.

Oregon Health Services Commission. 1991. Prioritization of Health Services. NP: Oregon Health Services Commission.

Ozar, David T. 1983. What Should Count as Basic Health Care? Theoretical Medicine 4: 129-41.

President's Commission for the Study of Ethical Problems in Medicine and Biomedical and Behavioral Research. 1983. Securing Access to Health Care, vol. 1. Washington, D.C.: U.S. Government Printing Office.

Schelling, Thomas C. 1979. Standards for Adequate Minimum Personal Health Services. Millbank Memorial Fund Quarterly/Health and Society 57: 21233.

The Oregon Basic Health Services Act. n.d. [Unpublished review of legislation including Senate Bill 27, Senate Bill 935, and Senate Bill 534 from the office of Oregon State Senate President John Kitzhaber.] 
Veatch, Robert M. 1974. Case Studies in Bioethics: Who Should Pay for Smokers' Medical Care? Hastings Center Report 4 (No. 5): 8-9.

Veatch, Robert M. 1986. DRGs and the Ethical Reallocation of Resources. Hastings Center Report 16 (3): 32-40.

Veatch, Robert M. 1990. Physicians and Cost Containment: The Ethical Conflict. Jurimetrics 30: 461-82.

Weinstein, Milton C., and Stason, William B. 1977. Foundations of Cost-Effectiveness Analysis for Health and Medical Practices. The New England Journal of Medicine 296: 716-21.

Wesley, John. 1785. Primitive Physick. London: J. Paramore. 